\title{
Letter to the editor regarding "Outcomes of patients with unexpected diagnosis of infection at total hip or total knee arthroplasty revisions"
}

\author{
Xing Wang ${ }^{1} \cdot$ Qiang Huang ${ }^{1}\left[\right.$. Fuxing Pei ${ }^{1}$
}

Received: 24 July 2021 / Accepted: 30 July 2021 / Published online: 11 August 2021

(c) SICOT aisbl 2021

I read with great interest an article titled "Outcomes of patients with unexpected diagnosis of infection at total hip or total knee arthroplasty revisions" by Loppini et al. [1]. Authors performed retrospective analysis of a prospective cohort that assessed the incidence and survival of patients with unexpected periprosthetic joint infections (PJIs) in a presumed aseptic revision of total hip (THA) or knee (TKA) arthroplasties. Although they have touched a highly pertinent topic in a scientific manner, the study has brought an important issue that I would like to communicate with the authors.

In the "Patients and methods" section, the authors described that the empiric antibiotic treatment has been interrupted after seven days in patients without evidence of PJIs. However, other authoritative studies have previously stated that extending peri-operative prophylactic antibiotics ( $>24$ hours) in patients undergoing TKA or THA for aseptic failures does not provide any additional benefit in terms of reducing the risk of subsequent PJIs [2, 3]. Inappropriate use of antibiotics may lead to the emergence of antimicrobial resistance and an increased risk of opportunistic infections [4]. Therefore, we do not think it is reasonable that

A statement of the location where the work was performed The work was performed in Department of Orthopaedic Surgery, West China Hospital, Sichuan University.

Xing Wang is the first author.

Qiang Huang

huangqiang4325@126.com

Xing Wang

15626406229@163.com

Fuxing Pei

peifuxingwestchina@163.com

1 Department of Orthopaedic Surgery, West China Hospital, Sichuan University, No.37, Guoxue Road, Wuhou district, Sichuan Province 610041 Chengdu, People's Republic of China the empiric antibiotic treatment has been interrupted after seven days in patients without evidence of PJIs. The Journal of "International Orthopaedics" is a very influential journal, and as such, we feel obligated to point out this issue in order to ensure that readers are aware of more rational use of antibiotics in a presumed aseptic revision of THA or TKA.

\section{Declarations}

Conflict of interest The authors declare no competing interests.

\section{References}

1. Loppini M, Pisano A, Di Maio M, La Camera F, Casana M, Grappiolo G (2021) Outcomes of patients with unexpected diagnosis of infection at total hip or total knee arthroplasty revisions. Int Orthop. https://doi.org/10.1007/s00264-021-05137-8

2. Kuo FC, Aalirezaie A, Goswami K, Shohat N, Blevins K, Parvizi J (2019) Extended antibiotic prophylaxis confers no benefit following aseptic revision total hip arthroplasty: a matched casecontrolled study. J Arthroplasty 34(11):2724-2729. https://doi. org/10.1016/j.arth.2019.06.012

3. Kuo FC, Lin PC, Bell KL, Ko JY, Wang CJ, Wang JW (2020) Extended postoperative prophylactic antibiotics with first-generation cephalosporin do not reduce the risk of periprosthetic joint infection following aseptic revision total knee arthroplasty. J Knee Surg 33(6):597-602. https://doi.org/10.1055/s-0039-1683889

4. Skråmm I, Saltytė Benth J, Bukholm G (2012) Decreasing time trend in SSI incidence for orthopaedic procedures: surveillance matters! J Hosp Infect 82(4):243-247. https://doi.org/10.1016/j. jhin.2012.08.011

Publisher's note Springer Nature remains neutral with regard to jurisdictional claims in published maps and institutional affiliations. 